5 Махмудова Г.Р. Значение инвестиционной политики в модернизации экономики страны // Молодой ученый. 2016. №8. С. 592-594

\title{
ROLE OF INVESTMENT IN THE COUNTRY ECONOMY
}

\author{
(C) 2020 Popova Ekaterina Sergeevna \\ Student \\ (C) 2020 Kalimullin Denis Maratovich \\ Candidate of Economics, Associate Professor \\ Samara State University of Economics \\ E-mail: popovaks07@yandex.ru, kdm2804@mail.ru
}

Keywords: investments, economics, investment risks, investment projects, scientific and technological base, investment resources.

This article is devoted to investments as a necessary condition for the development of the country's economy. Their key role at all levels of the economy, capable of expanding production processes, increasing the pace of scientific and technological progress, maximizing the profits of companies and increasing their own capital through competent investment in other companies, is considered. A summary of the historical event in the Chinese economy is given, as well as the formula for "successful investments" by Valery Zolotukhin, as one of the well-known investors of Russia.

УДК 333

Код РИНЦ 06.00.00

\section{ВЫЯВЛЕНИЕ РЕЗЕРВОВ СНИЖЕНИЯ СЕБЕСТОИМОСТИ ПРОДУКЦИИ ПРЕДПРИЯТИЙ ПРОМЫШЛЕННОСТИ ПУТЕМ НОРМИРОВАНИЯ МАТЕРИАЛЬНЫХ И ТРУДОВЫХ ЗАТРАТ}

\author{
(C) 2020 Порядков Михаил Александрович \\ магистрант \\ (c) 2020 Беланова Наталия Николаевна \\ кандидат экономических наук, доцент \\ Самарский государственный экономический университет \\ E-mail: poryadkovma@mail.ru,bnn371@yandex.ru
}

Ключевые слова: постоянные, переменные, издержки, себестоимость, "директ-костинг", нормирование, материальные, трудовые, затраты, нормативы, технологический процесс, консолидация, бухгалтерский, управленческий, производственный, учет.

Статья посвящена анализу такого понятия, как нормирование материальных и трудовых затрат основных рабочих в ходе процесса производства продукции на промышленных предприятиях. Рассмотрена методика выявления резервов снижения себестоимости продукции по результатам нормирования. 
В процессе производства продукции промышленные предприятия несут материальные и трудовые затраты, которые планируются и прогнозируются при расчетах производственной программы.

Значения материальных затрат объективно ограничены ффизической потребностью в тех или иных материалах, сырье, инструменте, энергии, необходимых для производства продукции с заданными техническими характеристиками. Эти нормы приобретают вполне определенные числовые значения на этапе разработки конструкторской и технологической документации.

Что касается трудовых затрат основного производственного персонала, то они также объективно предопределены отраслью промышленности, уровнем технического оснащения, организацией производства, оснащенностью персонала средствами и предметами труда, степенью специализации, в принципе технологическим процессом на конкретном производстве.

Данные постулаты неизбежно приводят к мысли о необходимости предварительного нормирования материальных и трудовых затрат на производстве, которое позволит более точно отслеживать отклонения затрат от заданных норм, как в части размера этих отклонений, так и места их возникновения (цеха, участка, конкретного человека), и последующих мероприятий для их нивелирования.

Поскольку в СССР была организована командно-административная экономика, то нормированию затрат уделялось самое пристальное внимание. Институты осуществляли научные разработки норм материальных и трудовых затрат, создавали инструкции, которые подлежали постоянной модернизации в соответствии с технологическим совершенствованием экономики.

Революционный переход к рыночной экономике практически остановил научные исследования в области нормирования, так как предполагал так называемый метод "проб и ошибок".

В настоящее время большинство ученых сходится во мнении, что законы, регулирующие рыночные отношения начали работать в РФ, что в определенной мере позволяет говорить об успешном переходе страны к рыночной экономике. Перед промышленными предприятиями остро встала проблема конкурентоспособности, наиболее эффективным решением которой является снижение издержек производства, а также повышение производительности труда. Нормирование материальных и трудовых затрат вновь стало актуальным для предприятий 1 .

Важно заметить, что в СССР нормирование затрат было исключительной прерогативой государственных органов. Сейчас же эта обязанность возложена непосредственно на предприятия, осуществляющие производственную деятельность. Эффективное нормирование материальных и трудовых затрат является существенным фактором роста конкурентоспособности предприятия.

На текущий момент времени множество промышленных предприятий в Российской Федерации используют нормативы, которые не соответствуют современным технологиям, поскольку в нынешних условиях постоянной модернизации и модисикации оборудования, оптимизации организации производства, появления новых технологий. Все вышеперечисленное требует полной и своевременной корректировки нормативов². 
Кроме этого, следует отметить, что в России в области нормирования на законодательном уровне действует "Положение об организации нормирования труда в народном хозяйстве"3, введенное в действие в 1986 г. Не отрицая полезность этого положения, следует сказать о том, что мировой опыт и рыночная ситуация диктуют новые условия.

В 1936 г. Д. Харрис ввел термин "директ-костинг", что переводится как "прямые затраты". Часто это понятие используют как метод расчета себестоимости. Однако в идеале - это способ ведения управленческого учета 4 .

Сущность "директ-костинга" заключается в том, чтобы на предприятиях затраты на производство разделялись на переменные и постоянные. Центральными категориями метода являются:

- постоянные издержки - затраты, не зависящие от объема производства продукции (фонд оплаты труда управленческого и административного персонала, отчисления в фонды, амортизация, арендная плата, проценты по кредиту и т.д.);

- переменные издержки - затраты, зависящие от объема производства продукции (фонд оплаты труда основного производственного персонала, отчисления в фонды, сырье и материалы, энергия и топливо, инструмент и т.д.);

- маржинальный доход - разность между выручкой от реализации продукции и переменными издержками.

"Директ-костинг" включает в себестоимость продукции только переменные затраты. Именно на их основе осуществляется планирование производства. В свою очередь постоянные затраты вычитают из маржинального дохода, полученного в периоде.

В России "директ-костинг" приобрел широкое распространение в следующих видах:

- Простой, который предусматривает раздельное ведение бухгалтерского и управленческого учета. При этом себестоимость рассчитывается только на основе прямых переменных затрат;

- Продвинутый, предполагает консолидацию производственного и бухгалтерского учета. В этом случае себестоимость исчисляется по прямым и косвенным переменным затратам ${ }^{5}$.

Очевидно, что продвинутый "директ-костинг" является более предпочтительным, поскольку, учитывая все виды переменных затрат, позволяет осуществить более точный расчет себестоимости продукции промышленных предприятий.

Но сложность разделения затрат на переменные и постоянные на различных предприятиях делает этот метод трудоемким, часто да такой степени, что целесообразность его ставится под сомнение, потому что полученный эффект может быть нивелирован управленческими и учетными издержками. Ведь в условиях конкретного предприятия часто отсутствуют четкие границы между постоянными и переменными издержкамиб.

Это означает, что очень важно регулярно переоценивать принципы разделения затрат и рассчитывать маржинальный доход.

В заключении хотелось бы указать на современные возможности программных средств производственного и управленческого учета. В частности, программный продукт фирмы "1С" - "Управление дискретным производством" позволяет осуществлять нормирование материальных затрат в разрезе номенклатуры, и трудовых затрат в разрезе технологических операций. Нормы которых прописаны в регламентных документах "Конструкторский документ" и "Описание технологического процесса" соответственно. 
Данное программное расширение непосредственно связано с бухгалтерским учетом, а процесс выпуска продукции осуществляет все необходимые проводки по списанию материалов и начислению заработной платы основному производственному персоналу.

Безусловно, реальная производственная деятельность подвержена влиянию различных факторов, вроде брака, отключения электричества, простоев из-за неисправности оборудования и прочее. Все это отклоняет издержки производства от идеальных норм. Программное обеспечение позволяет корректировать нормативные материало- и трудозатраты до фактических значений. В бухгалтерском и управленческом учете это происходит аналогично корректировке списания себестоимости на счет 90 на сумму отклонения фрактической себестоимости произведенной продукции от плановых значений.

1 Брезгина, М.О. [Текст] Нормирование труда как фактор роста производительности труда: современное состояние и перспективы развития / М.О. Брезгина // Социально-экономические науки и гуманитарные исследования. - 2016. - № 11. - С. 80-83.

2 Постановление Минтруда РФ от 25.11.94 N 72 "Об утверждении Межотраслевых укрупненных нормативов времени по документационному обеспечению управления" [Электронный ресурс]. URL: http://www.zakonprost.ru/content/base/part/343367.

3 Постановление Госкомтруда СССР, Президиума ВЦСПС от 19.06.1986 N 226/П-6 (ред. от 15.08.1989) "Об утверждении Положения об организации нормирования труда в народном хозяйстве" [Электронный ресурc]. URL: http://docs.cntd.ru/document/9043490

4Лапыгин, Ю., Прохорова Н. Управление затратами на предприятии. Планирование и прогнозирование, анализ и минимизация затрат [Текст]: учеб. пособие / Ю.Лапыгин, Н. Прохорова. - М.: Изд.: Litres, 2017. - 1214 c.

${ }^{5}$ Арутюнян, Ю.И., Тхакахова, М.О., Кузьмин, И.Д., Радченко, А.М. Теоретические основы системы "директ-костинг" [Текст] / Ю.И. Арутюнян и [др.]// Академическая наука - проблемы и достижения: Материалы XII междунар. науч. -практ. конф.. - Москва, 2017. - С. 188 -190.

6Дронова, О.Б. [Текст] Методика выделения основных бизнес-процессов организации и проектирования организационной структуры управления / О.Б. Дронова// Вестник Алтайской науки. №3. - 2018.-С.180-186.

\title{
IDENTIFICATION OF RESERVES FOR REDUCING THE COST OF PRODUCTION OF INDUSTRIAL ENTERPRISES BY RATIONING MATERIAL AND LABOR COSTS
}

\author{
C 2020 Poryadkov Mikhail Alexandrovich \\ Undergraduate \\ C 2020 Belanova Natalia Nicolaevna \\ Candidate of Economics, Associate Professor \\ Samara State University of Economics \\ E-mail: poryadkovma@mail.ru, bnn371@yandex.ru
}

Keywords: fixed, variable, costs, cost price, "direct costing", rationing, material, labour, costs, standards, technological process, consolidation, accounting, management, production, accounting.

The article is devoted to the analysis of such concepts as rationing of material and labour costs of the main workers during the production process at industrial enterprises. The method of identifying reserves for reducing the cost of production based on the results of rationing is considered. 